\title{
La caracterización de la mujer a través de su descripción física en cuatro cancioneros del siglo XV
}

\author{
A la Dra. Dña. María Eugenia Lacarra, \\ de la Facultad de Filosofía y Letras de Vitoria- \\ Gasteiz, que dirigió este trabajo.
}

TERESA IRASTORTZA

U.N.E.D., Centro de Vergara

\section{Introducción}

La mujer desempeña un importante papel en las composiciones amatorias como objeto de deseo. Puesto que la hermosura de las mujeres es la característica que con más frecuencia encontramos aludida, según puede percibirse desde una primera lectura, me parece sumamente interesante estudiar cuál es la caracterización física que hallamos en ciertos cancioneros del siglo $\mathrm{XV}^{1}$.

1 Cancionero de Lope de Stúñiga, Madrid, ed. Marqués de Fuensanta del Valle, J. Rayón, 1872, que en adelante citaré como CST.

Cancionero de Roma, Florencia, G. C. Sansoni, ed. M. Canal Gómez, 1935, 2t., que en adelante citaré como CR.

Cancionero de Baena, Madrid, C.S.I.C. ed. J.M. Azáceta, 1966, 3t. que denominaré $\mathrm{CB}$.

Cancionero de Palacio, Barcelona, C.S.I.C., Instituto Antonio Nebrija, ed. F. Vendrell de Millás, 1945, 2t., que denominaré CP. 
Además, el estudio de la descripción en estos cancioneros del siglo $\mathrm{XV}$ podría ayudarnos a conocer mejor la situación de la mujer en la época.

Para ello es fundamental analizar primero la función que las mujeres desempeñan en tales composiciones y descubrir luego los factores que llevan a este ingente número de poetas a elegir siempre unos modelos descriptivos cuando se refieren a las mujeres en general y a las amadas en particular. Sin el estudio de las causas de tales descripciones físicas podríamos caer en una incoherente enumeración y mezcla de epítetos.

Dado que en esta poesía amatoria cortesana se le dedican a la mujer tantos halagos, ruegos y reproches, es procedente, antes de comenzar con el estudio de la caracterización física de la mujer, tener en cuenta su papel en el proceso de creación del modelo femenino que se descubre en estas composiciones.

\section{La mujer en el proceso creador}

En primer lugar, destaca la ausencia de mujeres escritoras atestiguables en la poesía castellana de tipo cortesano, excepción hecha de Florencia Pinar, que no aparece en ninguno de los cuatro cancioneros citados. La escasez de mujeres escritoras que Snow calcula en proporción de seis por setecientos hombres en la época, y la misma escasez de sus textos, hacen imposible deducir una corriente de pensamiento y escritura «femenina» sin falsear las proporciones ${ }^{2}$.

En los cuatro cancioneros citados sólo se puede hallar un texto al parecer escrito por una mujer. Se trata de la «Epístola de la Reyna de Aragón, doña María, fija del Rey de Castilla, enbiada al Señor Rey don Alfonso marido suyo», en la que la reina, a punto de morir y tras esperar durante treinta años el regreso de su marido, se muestra conforme con su función de esposa, pues considera que a ella le viene la fama de la de su esposo y de las buenas acciones de aquél, por lo que afirma:

Pero aunque muera con esta raviosa manzilla \& con este intrínsico deo, de tanto grand título me alegro; que por tu fama será mi muerte sabida \& nombrada por todo el universo \& dirán: Muerta es la dolorosa, segunda María,

2 Snow, J.; "The Spanish Poet Florencia Pinar» in Medieval Women Writers, Manchester-University Press, ed. K. M. Wilson, 1984, pág. 320-332. 
muger de César Alfonso el magno, que asaz título es a mí ser reyna muger tuya \& morir por tuya, e yrte yo a esperar en aquel siglo do mi esperança será cierta, que non podrás fuyr.

(CR. 112r-112v: 91, 54-61) ${ }^{3}$.

Se evidencia en este texto que la reina de Aragón valora su persona de acuerdo a los modelos correspondientes a la función de la mujer como esposa que espera paciente al marido ausente en la guerra. Esto corresponde al tópico que compara frecuentemente a la mujer con personajes femeninos de la mitología clásica, esperando casta y pacientemente durante la ausencia del marido (como sucede, por ejemplo, con Penélope: CP 98: 224, 137). La reina María lo hace subrayando dos características: una, la castidad, aludida indirectamente al compararse con la virgen, con la que no sólo comparte el nombre, y la otra, la sumisión al marido, característica a la que también se alude en otras canciones dedicadas a ella como una de Santa Fe «Comiat entr'l Rey e la Reyna en el biaje de Nápols». (CP 126v-127v: 269).

Es decir, la actitud de la reina es igual a la que los hombres presentan cuando alaban a las mujeres en canciones y epitafios que difieren bastante de los dedicados a varones. De éstos se cuentan las hazañas gloriosas y de aquéllas la relación de sumisión - a menudo aceptada y puesta en boca de personajes femeninos- con respecto al varón. Así sucede en «A la tunba de la rreyna doña Juana» (CB 21r: 53), donde la información que se nos da sobre la reina se refiere exclusivamente al papel tradicionalmente asignado a la mujer, es decir, a sus roles de hija, madre y esposa sucesivamente, y donde la reina asume para su hija la misma función: «Mi fija fermosa doña Leonor / dexo bien cassada, ryca, bien andante» (CB 21r: 53, 25-26). Y en otros muchos textos de entre los que se pueden recordar «En loor [de] la Señora Reyna doña Catalina, madre de nuestro señor rey don Juan» (CB 24r: 63) o los que aluden a la reina doña Leonor: «Ffija del rey de Aragón» (CB 21v: 56, 9) «Muger de alto varón» (CB 21v: 56, 13), «Les nasçieron dos infan-

3 Las letras - ver nota 1- indican el cancionero. En cuanto a la serie de números, la primera indica el número del folio del original, excepto en el CST, en cuya edición no se refleja este dato, y por lo que he recurrido a la página de la edición. Tras los dos puntos se indica el número correspondiente al orden de aparición, dato que tampoco se halla en CR y CST. Tras la coma, se sitúa la cita en los versos. Si en esta última serie las dos crifras están separadas por guión, se trata de versos consecutivos, y si se separan por barra de versos no consecutivos. En los casos en los que, como en éste, el texto sea prosa, los últimos números señalan las líneas correspondientes. 
tes» (CB 21v: 56, 19). En otro caso ejemplificador de Fray Diego, «En loor e alabança de los siete fijos que ovo el rrey don Ferrando de Aragón», se refiere así a las hijas: «Son las señoras fermosas / doña María la mayor / otrosy doña Leonor, / que serán muy poderosas / casadas muy altamente / con grandes fijos de rreyes» (CB 167r: 514, 101-106).

Hay varias composiciones en las que la respuesta atribuida a una mujer es realizada por varones que se erigen en sus defensores y representantes ante difamaciones de terceros. Ejemplos de ello serían: «Respuesta que fizo por ella Pedro Morrera» (CB 34v: 101), «Este dezir de rrespuesta fizo e ordenó por la dicha dueña Françisco de Baena, escriuano del adelantado Diego de Ryuera, al dicho Alfonso Áluares de Villasandino, a la sobredicha rrequesta de desonores que fizo a la dicha dueña» (CB 35v-36r: 105), «Esta cantiga de rrespuesta fiso e ordenó el maestro Fray Diego en fauor e ayuda de la dicha Cortabota contra Martín el Çiego» (CB 162r: 500) o «Respuesta que dio por ella vn frayle» (CB 117v-118r: 330).

Hay otros casos en los que los poetas por medio del diálogo hacen intervenir directamente a personajes femeninos. Estas intervenciones responden casi sin excepción a personificaciones de cualidades éticas, como en el «Deçir. Enyego López de Mendoça» (CP 38v-40: 94). Son muy pocas las ocasiones en las que no se dan las personificaciones mencionadas, y en ellas el amante y la amada pertenecen al estamento nobiliario, como la de Iohan de Duenyas «Con grant reverencia e mucha mesura» (CP 46-v-48: 104), o las dos de Suero de Ribera «En una floresta 'scura» (CP 30-30v: 79) y «En una linda floresta» (CP 32-32v: 85) y otras. Cuando la amada es una villana las conversaciones son normalmente más sexualizadas y en estos casos rara vez aparece la mujer personificando cualidades éticas o comparada con personajes mitológicos.

Por otra parte, las respuestas que ponen los poetas en boca de mujer (como vemos, bien escasas) no aportan ninguna novedad de pensamiento, probablemente porque han pasado por el filtro de la pluma masculina. Por ello, no extraña mucho escuchar a la dama hablar de sí misma en el tono que habitualmente se le supone, en casos como éste de Iohan de Duenyas:

Senyor escudero, por tanto sería, segunt bien sabedes, mayor vuestro danyo, 
que mientre más fino es e bueno el panyo tanto más caro, senyor, costaría.

Lo mismo se puede afirmar de los dos únicos casos en los que el poeta expresamente quiere dar a conocer los pensamientos de la dama. En el «Debat d'una senyora et de su voluntat» (CP 56-56v: 119) de Estamariu la dama quiere salvar su honestidad, cuando dice a su voluntad: «Comiença mi voluntat / a desamar / pues comiençan mal tractar / mi honestat» (1-4), y en otro no firmado del Cancionero de Baena en el que la dama se lamenta de su suerte, de su «esposamiento» (CB 77r: 237).

De entre todos los textos de estos cuatro cancioneros sólo en una ocasión es la mujer quien inicia la composición con una pregunta y con ello la conversación entre hombre y mujer. Se trata del poema «Desir de moxica» (CR 63r-66v: 33). En este caso es la mujer quien induce al cortesano comenzando a hablar del amor, y éste quien le recuerda que ha de llevar una vida honesta si quiere la fama, por lo que la insta a abandonar tal actitud por considerar impropio al sexo femenino loar al dios Amor: «que si vos la vida honesta / del más cierto amor seguís, / bivirés loada vida / honrada de las del mundo / acrescentaréys lo segundo / nuestra firme ley complida» (67-72) ${ }^{5}$.

Como vemos, de las páginas precedentes se puede afirmar que la mujer, como objeto de deseo del varón, no tiene voz propia; no sabemos de ella más que aquello que el poeta nos transmite. La única excepción son estos textos de la reina María, pero ésta acepta el papel que los hombres han asignado a las mujeres nobles. Sólo Florencia Pinar pone en cuestión la pasividad femenina requerida como virtud inherente a las mujeres en la opinión de los poetas, y afirma sus propias necesidades a pesar de las dificultades que ello conlleva ${ }^{6}$.

4 Esta imagen es la misma que encontramos, por ejemplo, en esta composición de F. de la Torre que dice: «Lo que tiene otro sobrado, / a mí poco me aprovecha (CR 102-103r: 75, 205-214).

5 Hay otro caso, pero de distinta índole: «Este desir fiso e ordenó el dicho maestre Fray Lope del Monte, por contenplaçión de dos dueñas que se le venían a quexar e querellar de sus maridos, e le pedían consejo que es los que deuían faser» (CB 129r-129y: 349).

6 Cancionero castellano del siglo XV, Madrid, ed. R. Foulché-Delbosc, 1912-1915. 2t., págs. 577-579, y Deyermond «Spain's First Women Writers», in Images: Wo- 
La escasez de mujeres que pueden y osan tomar la palabra hace difícil conocer la opinión que tuvieron del modelo bajo el que se las examinaba y por el que eran halagadas o denostadas. Según los pocos datos que se pueden obtener de estos cuatro cancioneros parece deducirse, sin embargo, que las mujeres asumirían, interiorizarían esos modelos que desde fuera les eran impuestos.

\section{Condicionantes de la descripción de la belleza femenina}

Una de las características fundamentales de la mujer para los poetas de los cancioneros es la belleza inigualable de la amada, que abarca los ámbitos físico, social y moral. Y aunque la causa aparente que motiva el amor es la belleza física, el linaje noble y la virtud son asimismo condiciones indispensables y con frecuencia subrayadas, como luego veremos. La aparente preeminencia de la belleza física se observa en numerosos ejemplos entre los que están:

Des que vi tu fermosura acordé de te amar

(Ugo Durriés, CP 51v: 110, 5-6).

Ayas piedat et mesura contra mí, que de tu sola figura me vençí

(Lope de Stúñiga, CST 1:1, 5-8)

Pues si yo tanto vos quiero vuestra belleza lo faze (Joham de Mena, CR 12v: 5, 111-12)

Mis oxos fueron a veer ffermosura tan estranya que de bien poca manya yo fuy preso en su poder (E. Lopeç hermano de Mendoça, CP 3: 5, 1-4).

No obstante, y aun admitiendo que la belleza física es la causa inicial del amor, hay que tener en cuenta que el cortesano no se enamora de cualquier bella, sino de la belleza de las mujeres nobles. Las otras

men in hispanic literature, Berkeley, University of California Press, ed. B. Miller, 1983.

Hay también una composición de Iohan de Duenyas (CP 46v: 104, 15-16/31-32/109) en la que el poeta hace hablar a la mujer de una manera irónica respecto a las declaraciones de amor de los hombres. 
pueden ser bellas y de tal modo aparentar hidalguía como sucede en el poema siguiente:

\author{
El amor e la ventura \\ me fisieron yr myrar \\ muy graçiosa criatura \\ de lynage de Aguar; \\ quien fablare verdat pura \\ bien puede desir que non \\ tiene talle de pastora.
}

(CB 14v-15r: 31 bis, 4-10)

O en esta otra «Serrana» de Enyego López de Mendoça, en la que tras admirarse de la belleza de una serrana, el poeta dice:

Iouro por Sant'Ana

que no soys villana.

(CP 13: 31, 23-24).

Es decir, que la condición estamental apremia mucho a la hora de amar, como se puede percibir en serranillas y villancicos en los que se habla de pastoras:

\author{
Desde aquí quiero iurar, \\ sy voluntad no me enganna, \\ de iamás amar villana. \\ Porque amor et gentilesa \\ todo van por una vía, \\ e la villana vilesa \\ busca su ygual compannía; \\ pues de tal gente curar, \\ non consyente ya mi gratia \\ de iamás amar villana.
} (Carvajales, CST 367: 139, 1-3 / 11-17).

$\mathrm{Y}$ esta primera barrera se impone conscientemente, pues para descalificar la belleza de una dama se la suele comparar con las villanas, tal y como sucede en el «Desyr que fiso el dicho Ferrand Peres a su amiga», o en la «Respuesta secunda de Suero de Rrybera» (CB 191: 575):

Delante los oydores vos niego la conseqüençia, que aya tal preminençia la que amades por amores; dexad christianas e moras, ca fallaréys de pastoras más de quarenta mejores.

(CB 191v: 575, 22-28) 
La nobleza, pues es característica primordial a la hora de hacer un estudio sobre la belleza de la mujer. Desde este punto de vista no se debieran leer «alta», «de alto estado», etc. como metáforas sino como signos que tienen un referente tan claro e inmediato como lo puedan tener las calificaciones morales o físicas. Entre otros, se pueden hallar:

\author{
Vy ante os ollos meus \\ una rrosa que fys Deus \\ fermosa de alto estado. \\ (A. Áluares, CB 12v:24, 18-20) \\ Muy alta \& muy excelente \\ princesa muy generosa, \\ más gentil \& más fermosa \\ que el sol quando es luziente. \\ (I. Tapia, CR 82r: 51, 1-4) \\ Plumaies de fidalguía \\ trayan con tan buen ayre \\ llamando grande apellido, \\ que me priso su donayre \\ e dexome así ferido \\ que tarde seré guarido. \\ (Inyigo López, CP 71: 148, 18-23)
}

A vos, muy noble señora, bien guardada e sabidora, discreta, de gran linage, graçiosa, de buen vissage, do toda bondat demora. (A. Áluarez, CB 54r: 174, 28-32)

La importancia de que la mujer pertenezca al estamento nobiliario para ser considerada digna de amar es tal que la descripción de la belleza física varía sustancialmente según el estamento que ésta represente.

Así, una de las características que más salta a la vista es que frente a los casos en los que se da una descripción idealizada y sin referente de la belleza de la amada noble, la descripción de serranas, pastoras, etc. abunda en pormenorizaciones físicas concretas.

Resulta asombrosa la clara distinción que se podría hacer en los cuadros expuestos si se leyeran uniendo las descripciones aglutinadas en torno al nombre o adjetivo correspondiente (fermosura, cuerpo...) alrededor de un mismo poema. Por ejemplo, si en el CR buscamos las citas entresacadas del $126 \mathrm{v}$ podemos deducir con gran seguridad que «beços, gordos, bermejos», «ojos negros \& rasgados», «cavellos ruvios, peynados» se hallan referidos a alguna pastora, puesto que la frecuencia de términos descriptivos es muy alta y la descripción es más realista que 
las de las dedicadas a las amadas cortesanas. Además, si en este mismo cuadro uniéramos cuantas caracterizaciones surgen alrededor del folio 128r no nos cabría duda alguna de que se trata de la descripción de una serrana, al leer cosas como "rucia cabeça traya tresquilada», "piernas pelosas bien como salvaje», «tetas disformes atrás las lançava». Es decir, se vitupera a la mujer en términos sexuales y de descripción física, como sucede en esta composición de Villasandino "Contra una dueña d'este reyno por manera de la afear e deshonrar por rruego de un cavallero que ge lo rogó muy afincadamente», del que transcribo a modo de ejemplo estos versos:

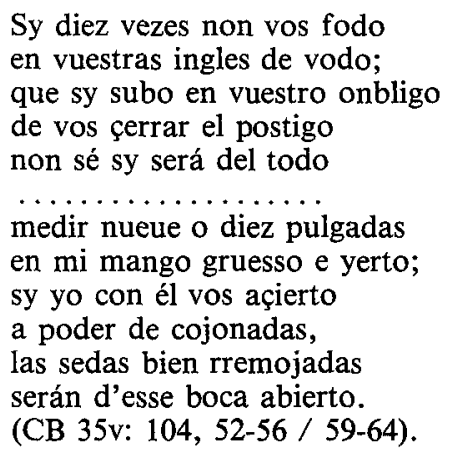

La alabanza de la belleza de la amada noble, carente de verdaderas pormenorizaciones físicas que la corroboren, contrasta con las referidas a mujeres no cortesanas. Además, esta ausencia de rasgos físicos parecería paradójica ante el empeño de defender a la amada como la más bella.

Los pocos rasgos descritos sorprenden por su vaguedad e inconcreción. Si el rostro es bello no sabemos en qué consiste tal belleza, si los ojos enamoran no encontramos la explicación... Sólo ocasionalmente se puede hallar mención de alguna parte del cuerpo que no sea el rostro o las manos. El rostro de la amada recibe distintas denominaciones (rostro, cara, semblante, viso, fayciones...) pero esta variedad de acepciones en ningún caso se corresponde con una concreción descriptiva, como se puede observar en estos ejemplo: «fayçones tiene de muy plazient ayre» $(155: 324,18)$, «de muy grande alegría» (CP 12v: 23, 5), «lindo rostro» (CR 8v: 4, 144), «en su semblante fermosa artera» (CP 155: 324, 16), «linda cara» (CR 11v: 5, 63). Lo que destaca en el rostro es su color, los ojos y con menos frecuencia la nariz: «muy resplandesciente» (CR 82r: 51, 20), «vuestra color matysada» (CB 8r: 8, 11), «fas 
muy blanca, lisa» (CB 185r: 551, 45) o algunos otros como «faç bien tallada» (CP 155: 324, 20). En algún que otro caso el cabello, las pestañas, cejo (ambas en CB 76r: 234, 36-39/64-70) y mucho más ocasionalmente la garganta (CB 78r: 241, 9).

En ocasiones el referente descriptivo se amplía al cuerpo, al talle «fermosa en tallyo e muy delicada» (CP 155: 324, 17), «El cuerpo estrecho» (CP 155: 324, 20), «ygualdat en su fechura» (CR 105r: 75, 320), «lisso muy enviso» (CB 164v: 506, 3-4), «muy lysa» (CB 143v: 415, 19), y en casos muy excepcionales a los pechos, que son siempre albos y casi siempre de cristal (CB 78r: 241, 9, 89r: 269, 27-28).

No sucede lo mismo con la descripción de mujeres que no sean de la nobleza, en cuyo caso las partes del cuerpo a las que se alude, cuando son las mismas que se describen al referirse a la amadas, tienen casi siempre como finalidad efectuar una comparación ridiculizante, mostrando el contramodelo tanto físico como moral de las mujeres cortesanas. Esto sucede en la mayoría de villancicos y canciones dedicadas a pastoras y mujeres no cortesanas, salvo algunas excepciones. Para ejemplificarlo nada mejor que alguno de estos poemas dedicados a serranas:

Partiendo de Roma, passando Marino, fuera del monte, en una gran plana, executando tras un puerco espino, a muy grandes saltos, veniá la serrana. Vestida muy corta de paño de ervage, la rucia cabeça traya tresquilada, las piernas pelosas, bien como salvaje, los dientes muy luengos, la fruente arrugada; las tetas, disfformes, atrás las lançava, calva, cejunta, \& muy nariguda tuerta de un ojo, ymbifia, barbuda; galindos los pies que diablo semblava

(Carvajales, CR 128r: 120).

Maguer feo, non te creo que non suene tu dotrina; quando oteo tu meneo es de loca saluagina.

el tu nido es tan seguido que non cria telarañas.

Por mí digo que maldigo a quien joyas te presenta, e castigo a todo amigo que se guarde de tormenta; vyl serpenta, bien qüarenta 
entraron por tu postigo;

con tal rrenta te contenta

pues non tienes otro abrigo

(CB 34r-34v: 100, 5-8, 23-24/33-40).

Teresa, pues tienes fama

de grant puta natural

(Fray Diego, CB161v: 499, 1-2).

Yo querrya rrecalçar

en esse vuestro aluañar

mi pixa quier grande o chica:

commo el asno a la borrica

vos querrya enamorar,

non vos ver mas apalpar

yo desseo vuestra crica

tener mi carajo arrecho

bien metido en vuestro coño

tener mi carajo arrecho

bien metido en vuestro coño

sy el culo non vos atapo

con aquestos mis cojones,

a los cinco empuxones

non vos rremojaré el papo

(A.A. Villasandino, CB 35r-35v: 104, 10-16/19-20/ $35-38)^{7}$.

Es, en general, una descripción peyorativa, bien de los órganos sexuales bien de otras partes del cuerpo con connotación sexual.

Excepcionalmente una mujer noble es descrita de manera similar a las villanas. Cuando esto se da, la intención del poeta es claramente difamatoria. Lo hemos visto ya en el poema citado de Villasandino, y se ve también en otro caso en el que alude dos veces a su mujer tratándola de fea (CB 29r: 79); u otro como el que Pero Veles de Guebara compone a «vna dueña muy vyeja [...] e non avya en el rreyno quien quisyese con ella cassar, tanto era ffea e de vyeja e de pobre, non enbargante que era dueña de muy buen linaje» (CB 112r-122v: 322).

Aunque se puede hallar en algunas ocasiones a las villanas tratadas con mayor respeto del habitual, también en estos casos se enfatiza el verdadero obstáculo del amor, que resulta ser la diferente clase social. Los poetas demuestran una y otra vez que el verdadero amor procede de las nobles y que de las villanas sólo puede proceder villanía:

7 Igualmente $35 \mathrm{v}-36 \mathrm{r}: 105 ; 45 \mathrm{r}: 139 ; 133 \mathrm{v}: 360,5-8 ; 133 \mathrm{v}: 362,9-16$. 
Replico: yd en buen hora, non curéys de amar villana; pues servís a tal señora, non troqués seda por lana; nin queráys de mi burlar, pues sabéys so enagenada (Carvajales, CR 110r: 88, 21-26)

Por ello, la necesidad de «purificar» el cuerpo de la amada, de ocultarlo incluso, contrasta con la de descubrir los órganos sexuales de las otras, su «cosa» como frecuentemente es denominada (CR 98r: 75, 110; 103 r: 75, 227; 118r: 101, 16). Esta cosificación se observa tanto a nivel léxico como de registros a la hora de hallar imágenes, hacer comparaciones. Las amadas podrán ser estrella, sol, luna, flor, pájaro. De las villanas dicen vergajo, carajo, postigo, cabalgadura. Por ejemplo, en este texto de Ferrand Manuel:

Jurando lo digo al santo Fedrique, que yo nunca tenga la nouia muy presta sy a vuestra amiga non punço en la cresta fasta que la madre sse le molifique (CB 133v: 360, 5-8).

O esta descripción anónima que narra una escena que el poeta vio acontecer entre villanos:

\author{
Vna falsa mamantona \\ mamando commo lechón, \\ e segunt mi entençión \\ la teta que ella mamaua \\ de largura bien lleuaua \\ vn grant palmo en el peçón \\ (CB 45r: 138, 7-12).
}

Y otros muchos como:

Señor Juan Alfonso, pintor de taurique, qual fue Pitas Payas, el de la fablilla, maguer vos andades acá por la villa a vuestra muger bien ay quien la nique, que ella se flota debaxo el chazminque a muy fuertes golpes con los de la mesta; por ende, sed çierto, sy a mí me lo enpresta, que juegos le fa el çiquesique

(Ferrand Manuel, CB 133v; 362, 9-16).

$\mathrm{Si}$ achare bon abrigo en la dona que otro abriga (A. Áluares, CB 46r: 143, 5-6).

Diego, sí Dios me adiestre, 
que devéys aver plazer

que un duque \& un maestre

gozen de vuestra muger;

ovistes buena ventura

que vos fizo Dios ygual

que un grande \& un real

ayan tal cavalgadura,

dulce tiene el angostura

(A. de Montoro, CR 144r-144v: 158)

\section{II.1. Omisión descriptiva y descripción «comparativa»}

Entre las descripciones de nobles cortesanas no son abundantes los epítetos que acompañan a la denominación de una parte del cuerpo de la amada. Las metáforas casi nunca se refieren a un rasgo físico concreto, sino más bien a la belleza en general o a una descripción que quiera sobre todo alabar la belleza ética.

Entre éstas son importantes las referidas al firmamento, y no es muy difícil averiguar la causa racionalizada de estas metáforas. Comunes a cualquiera de los elementos del firmamento son su lejanía y altura - características estas no muy distintas a las que recibe la amada en los cancioneros: siempre lejana, distante, en un pedestal o castillo-.

Otra de las similitudes es la de la claridad que las hace distintas y visibles, diferenciables en la oscuridad. Desde esta perspectiva la amada a la que se comparan otras damas y mujeres resaltaría por su luz. Motivaciones bien obvias de la claridad y blancura son las que hacen referencia a la pureza, a la castidad tan obsesivamente recalcada.

Entre las estrellas - es decir, entre las damas cortesanas- hay, empero, una que brilla más, que es el sol, como lo dijo Fernando Péres:

Pues de dueñas e donsellas

mi señora muy loada

asy es aventajada

como el sol de las estrellas

(CB 181r: 573, 11-14).

O estas otras:

E vi una duenya que así resplandía como el sol en mayo en su alta espera, e como él así bien se'smera entre las planetas así bien se'smeraua

(F. Ymperial, CP 155: 324, 11-14). 
Vy un día rresplandor

tan claro, que passaua

según meu entender

todos los resplandores

(A. Álvares, CB 12v: 23, 10-13).

También abundan las comparaciones de las amadas con personajes mitológicos de la antigüedad, lo cual es una forma de deshumanizar por sublimación, minimizando lo concreto de su naturaleza humana para demostrar su naturaleza divina:

Del sege de Capuana

vi Camilla graciosa, que resplandesce fermosa más que estrella de Diana

(Suero de Ribera, CR 73r: 41, 49-52).

Non Penélope, nin Ysifle menos, non la prudente castíssima Argía tovieron goardados con tanta porfía sus inmaculados limpíssimos senos (Iohan de Andújar, CST 192-194: 49, 13-16).

Otro tipo de metáforas muy frecuente se refiere al mundo vegetal. Son tan utilizadas que parece que flor, rosa, jazmín, funcionan como sinónimos de belleza, pero en estas metáforas se puede hallar un matiz especial, es el canto de la belleza como fin en sí, sin otra finalidad que la belleza misma, la que encarnan las mujeres, amable por su gratuidad, por su capacidad estética. Simbolizan por otra parte (lo que se subraya siempre como componente genuinamente femenino) la fragilidad de la mujer, su necesidad de protección, debida a su estado pasivo, vegetativo. Por otra parte, encontramos que son también utilizadas como la mayoría de las imágenes que simbolizan la hermosura femenina en un sentido comparativo, frecuentemente de carácter superlativo:

Flor das flores

(A. Álvares, CB 12v: 23, 17)

Das flores flor

(A. Álvares, CB 19: 45, 23)

Lynda flor que non a par

(A. Álvares, CB 20v: 51, 20)

La flor de las flores

(F. Inperial, CB 76r: 234, 48)

La que es flor e pres d'España, corona de las ffermosas,

muy más linda que las rrosas 
bryosa sin toda saña

(Ferrand Péres, CB 189r: 569)

Flor de las flores

(Johan de Tapia, CR 85v: 58, 15)

Entre las flores se demostraua

en su semblante fermosa artera

(F. Ymperial, CP 155: 324, 15-16)

Esta lista se podría alargar aún mucho ${ }^{8}$, completándola con textos en los que aparecen estas metáforas de tipo vegetal a modo de aposición, y en las que se puede observar que flor, rosa, jazmín, funcionan como sinónimos de «bella», «hermosa», con los matices citados.

Hay otros tipos de metáforas que no aparecen con la profusión de aquéllas referidas al mundo vegetal o al firmamento. Entre ellas, por ejemplo, un grupo selecciona las piedras preciosas, siempre en un sentido comparativo:

\author{
Vos mostráys joya preciosa \\ de las bellas esmerada \\ (Carvajales, CR 108r: 85, 29-30). \\ Çafir gentil, claro beril \\ es la su lynda fegura, \\ vna de mill muy doneguil, \\ exçelente criatura, \\ mucho pura syn orrura, \\ su color como brasyl, \\ por natura syn mesura, \\ linda ymagen de marfyl \\ (Fray Diego de Valencia, CB 164v: 506, 25-32).
}

Otras imágenes son particulares y aparecen en algún que otro autor, como la canción de lohan de Tapia «Muy alta \& muy excelente» (CR 82r-82v: 51), que compara la belleza de la amada con el agua, la claridad; otras que tienen referente animal, generalmente las aves. Pero, aun en este tipo de imágenes, el común denominador reside en la necesidad de diferenciar a la amada del resto de las mujeres, incluso de las mujeres que los cortesanos consideran «amables».

CB 5v: 5, 24/42; 8r: 7bis, 31-33; 8r:8, 16; 10v: 17, 2; 11r: 17, 20/24-27; 12v: 24, 18-20; 14v: 31bis, 11-17; 15r: 32, 14; 20v: 50, 29; 47v: 149, 44; 53v: 171, 9; 75r: $231,10-12 ; 75 \mathrm{r}: 234,10 ; 76 \mathrm{r}: 234 ; 103 \mathrm{r}: 297,1 ; 153 \mathrm{r}: 464,9-11 ; 185 \mathrm{r}: 551,29 ; 185 \mathrm{r}$ : 552, 34; 188r: 565, 6; 189r: 570; 191r: 573, 35 .

CP 78: 158, 2; 102v: 234, 14. 
Concluyendo, podriamos afirmar que cuando la descripción de la mujer excede de lo que se fija como norma de la descripción cortesana, tiene una intención denigrante y claramente antitética del ideal femenino establecido.

Me parece necesario reiterar cómo cuando la mujer se considera objeto digno de amor por parte del hombre, tiene que ser sublimada hasta el punto de suprimir toda posible descripción física que permitiera identificarla como mujer real. En el caso en que la descripción es más concreta, tampoco permite plasmar a la mujer real, dado que en estas ocasiones los poetas exageran los rasgos físicos de manera grotesca.

\title{
II.2. La divinización de la dama como proceso de deshumanización
}

De lo dicho hasta ahora hay que concluir que la dama de la poesía cancioneril está deshumanizada. Esta conclusión no está en contradicción con las continuas menciones de la belleza y hermosura de las nobles damas que aparecen en estos cancioneros, con frecuencia exaltadas hasta la divinización. El motivo radica en que no se alaba a la dama por ser mujer, sino por no ser una mujer común; por ello, no se puede hablar de la idealización de la mujer cuando se la menosprecia hasta el punto de que para alabarla hay que enaltecerla y divinizarla, hay que deshumanizarla y considerarla diferente del resto de las de su sexo.

Es necesario que la amada sea poco común y que sean Dios o la Naturaleza quienes la hayan elegido, confirmando así las aseveraciones del poeta. Por ejemplo:

\author{
Si Dios nuestro saluador \\ oviera de tomar amiga, \\ ffuera mi conpetidor \\ (Álvaro de Luna, CP 1v: 2, 1-3).
}

Lida propone ocho fórmulas de ensalzamiento y dignificación de la mujer en la literatura del siglo $\mathrm{XV}^{9}$, aunque algunas de las categorías de las que habla son difíciles de hallar en estos cancioneros.

Todas son en definitiva variaciones alrededor de un mismo tema cuya finalidad es caracterizar a la dama como la más bella de cuantas

9 Lida de Malkiel, M. R. «La dama como obra maestra de Dios», in Estudios sobre la literatura del siglo XV, Madrid, Porrúa Turanzas, 1977, págs. 179-290. 
han sido y son. Querer loar a la amada por ser la más hermosa lleva a los poetas a efectuar comparaciones en el tiempo y en el espacio, en la naturaleza y en la historia, subrayando la preferencia que Dios le ha conferido (CST 6: 2, 26-27; 192: 49; CP 34: 88, 5-12; 157v: 327, 9-10; CR 204v: 180, 313-320).

Por no incurrir en la contradicción de alabar a las mujeres por loar a la amada, el poeta suele justificarse responsabilizando a Dios por haberla hecho no común a las demás (CP 82v: 172, 16, 5-8), e incluso afirmando que la amada ha sido obra directa de Dios o de la Naturaleza, no mediatizada:

\author{
Mucho deuedes loar \\ a quien uos fyso syn par \\ (A. A. Villasandino, CB 8r: 7 bis, 29-30). \\ Que si Dios vos ha dotada \\ de tan alta fermosura, \\ ¿Qué vale la criatura \\ que de todos non es amada? \\ (I. Tapia, CST 206: 54, 24-27). \\ Fyso vos Dios delycada \\ (A. A. Villasandino, CB 8r: 8, 9). \\ Que Deus vos fes de tal valor \\ que todo el mundo inda amor \\ vos van sempre obedesçer \\ (A. A. Villasandino, CB 11v: 19, 19-20). \\ La linda muy acabada \\ que Dios bendixo en la cuna, \\ non ovo culpa ninguna \\ por mirar planeta onrrada \\ (A. Moranna, CB 89r: 270, 17-20). \\ Sola vos, gentil señora \\ sé que os tovo Dios guardada \\ (Carvajales, CR 108v: 85, 51-52). \\ Más gentil senyora mía, \\ que Dios crió tan fermosa \\ (Gonçalbo de Quadros, CP 57v: 124, 9-10).
}

Para conferir a Dios esta función parece necesario insistir en el papel distintivo asignado a la amada, por lo que su creación se justifica por una finalidad específica, con atención y miras especiales:

Todos me dizen que Dios no formó tan lindo gesto

(Iohan de Torres, CP 18v: 51, 3-4).

Antes del universal mundo es una espeçial 
en graçia et condiçiones, et fermosa de fayçones et muy buenda de bondat

(A. Enríquez, CP 76v: 154, 174-178).

Dios la fizo sin fallir en beldades acabada, muy donosa en reyr, en su gesto sosegada, en sus fechos aseada, honesta en faular como sabe conportar al que d'ella es amado. (Sarnés, CP 161: 333, 5-12).

Porque su par non nasció nin virtud tanta no dio Dios a quien más quiso dar (Carvajales, CST 343: 126, 13-15).

$\mathrm{Si}$ antes ovierades sido, fiziera razón humana, segund el gesto garrido, vos ser madre de Cupido \& gozar de la mançana; que si Paris conosciera que tan fermosa señora por nascer aún estoviera, para vos, si lo sopiera, la guardara fasta agora. Quanto más bella se para de las estrellas la luna, tanto vuestra linda cara se muestra perla muy clara sobre las fermosas una; como el fenis fizo Dios en el mundo sola un ave, así quiso que entre nos sola tal fuesedes vos de fermosura la llave (Joham de Mena, CR 11v: 5, 51-70).

Una finalidad específica podría ser promover la salvación del hombre, por actualizarse en la dama la visión paradisíaca:

Si Dios amí tanto quiere como yo aquien me priso, en verdat del parayso auré quanto me plugiere (García de Pedraza, CP 98v: 225, 1-4).

Criado bien mirey su gesto, su falar e noble rrysso, lindo rrostro, claro, onesto 
Según Lida «quizás la más frecuente variante del motivo estudiado es la que afirma que Dios o la Naturaleza han creado a la hermosura como muestra de su poder o sabiduría» ${ }^{10}$. No hay, sin embargo, tantos ejemplos que permitan defender esta posibilidad como la más frecuente. Son pocas las muestras a las que se puede acudir; además de la que veremos en Andújar, se pueden citar:

\section{El Señor muy soberano, mostrando su grand poder, las otras mandó fazer, y ésta fizo por su mano} (Suero de Ribera, CR 73v: 41, 53-56).

Formaste la creatura atu senblança, señyor, de la tu santidat pura me feziste amador, quien figura tal figura tal qual tú la figuraste es causa de dar lugar para'lgún tiempo olvidar ati que me l'a mostraste. (Álvaro de Luna, CP 90: 203, 14-22)

La beldat ser toda vuestra, segund dize la escriptura \& segund opinión nuestra, a vos fizo Dios por muestra affinando su pintura.

(Carvajales, CR 108v: 85, 46-50).

Un caso excepcional citado por Lida, en el que la belleza de la amada se compara con la de los planetas, con la de mujeres de otros países y épocas, y en la que afirma que en esta dama se reúnen las gracias dispersas en el resto de las mujeres, es el poema de Alfonso de Montaños del que cito las dos primeras estrofas. Pero en este caso nos hallamos ante una idea más bien personal que tópica:

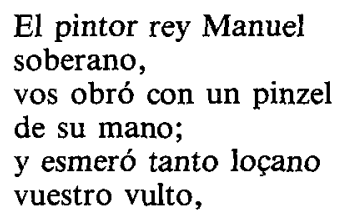

10 Ob. cit. pág. 235. 


$$
\begin{aligned}
& \text { qual jamás non fue trasulto } \\
& \text { en humano. } \\
& \text { De las damas afamadas } \\
& \text { escogió } \\
& \text { sus faciones más loadas } \\
& \text { que sentió, } \\
& \& \text { en vos las ayuntó } \\
& \text { con aseo } \\
& \text { do virtudes gran arreo } \\
& \text { permitió } \\
& \text { (CR 95r-95v: } 74,1-16 \text { ). }
\end{aligned}
$$

Lo que sí se puede afirmar categóricamente es que la dama ha de poseer una naturaleza superior a la humana, incluso divina, que justifique que el hombre noble pueda ponerse a su servicio. Las más frecuentes caracterizaciones deshumanizantes de las cortesanas son, por tanto, las que se refieren a su naturaleza sobrehumana:

Clara lus de paraysso

(A. A. Villasandino, CB 15r: 32, 25)

Vista angelical

(A. A. Villasandino, CB 15r: 33, 16)

Clauellina angelical

(A. A. Villasandino, CB 20r: 50, 6)

Lynda flor de paraysso

(A. Moranna, CB 89r: 270, 30)

Más fermosa que parayso

(CB 89v: 271, 31)

Angélica fygura

(Maestro Fray Diego, CB 164r: 504, 4)

Lus angélica

(F. Inperial, CB 77v: 238, 15)

Que sólo por fermosura

bien mereçedes ser santa

(I. de Torres, CP 18v: 50, 3-4)

Gesto angelical formado

(P. de Santa Ffe, CP 45: 101, 25)

Non es humana la lumbre que de vuestra faz procede (J. de Tapia, CR 91r: 64, 1-2)

Las posibilidades citadas están todas muy relacionadas, de tal modo que encontramos varias simultáneamente en un párrafo. Por poner un ejemplo claro, el poema de Iohan de Andújar «A la condesa de Andújar», ya citado: 
Sennora Condesa, en vuestras facciones en el gesto pulcro con grande armonía muestra haber fecho por sus proporciones el última fuerça sotil simetría; las estrellas potentes la grand gerarchía con los elementos mostraron la prueba del su grand poder, fasiéndovos nueva sobre las otras que el mundo nos cría

(CST 193: 49, 33-40)

Como se ha visto, cuando no se da el motivo de la divinización diferenciante se muestra a la amada en comparación con otras de distintas épocas y lugares, ya que el poeta necesita que su dama sea un especímen único entre todas para justificar que la pueda amar.

Ésta es la causa de tantas y tantas afirmaciones en las que se repite la excepcionalidad de la noble amada; de que el amante deba buscar su linaje en la creación divina, de que tenga que ser superior en todo a todas, pero dejando bien sentado que el término de comparación excluye a los hombres, ya que como bien aclara este estribillo:

En los señores, largueza;

en donas, grand fermosura

(Mosén Rabellas, CR 71v-72r: 39,

11-12)

En esa necesidad justificativa radica la diferencia que hacen los poetas cuando hablan de mujeres, de damas y de una mujer en particular a la que han elegido como señora: «Vos soy la que yo elegí / por soberana maestresa» (Johan de Tapia, CR 91r: 64, 9-10). Del resto pueden opinar lo que les plazca, pues son sólo mujeres, es decir, «hombres inperfectos». Un claro y extenso ejemplo lo podemos encontrar en el «Juego de naypes» de Fernando de la Torre, donde no se habla de la mujer, sino de sus distintos estados posibles con respecto al hombre - monja, doncella, casada, viuda - y donde se aprecia claramente que la imaginería cortesana del siglo XV es simplemente el aparato retórico mediante el cual los hombres se autodefienden de amar a una mujer, a ser inferior. Sólo unos ejemplos, referidos el primero al amor por las monjas, al de las viudas el segundo, el siguiente al de las casadas, y el último al amor por las doncellas:

Es verdat; si fuese bella y noble de condición, yo siempre sería della si[n] t temer la perdición; 


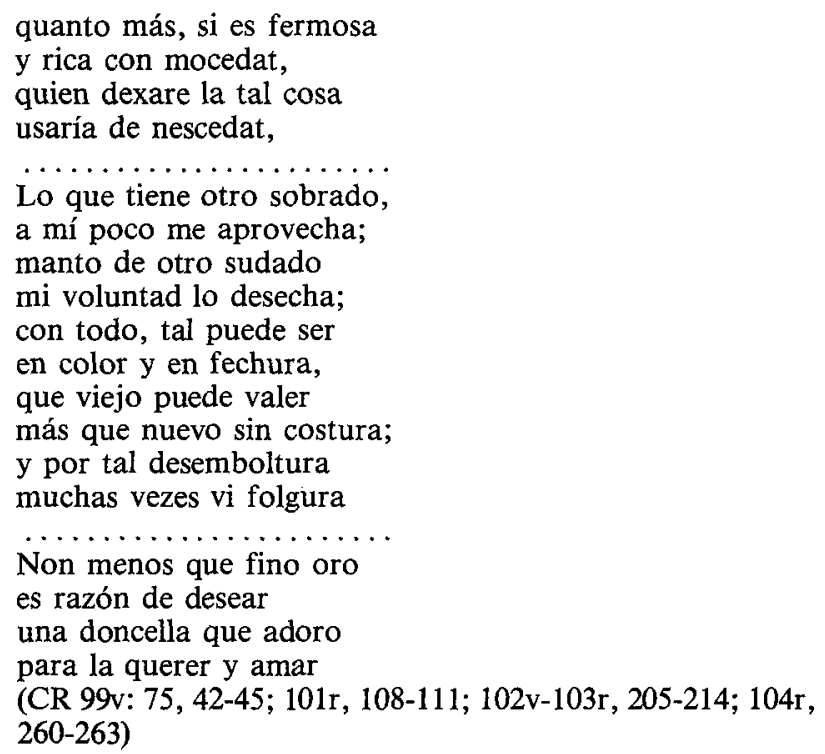

En una ocasión el poeta, al loar a la amada y distinguirla del resto de las mujeres, como los poetas necesitan hacer tan frecuentemente ${ }^{11}$, utiliza un rasgo específico: la sabiduría, requerida, normalmente sólo a los hombres. Para ello deja bien claro que esta característica es excepcional de su amada:

De sus amigas diré

que no s'igualen contigo

no puedo non te querer,

que fermosura et saber

en pocas fue, yo m'obligo

(Álvaro de Luna, CP 88v: 197, 3-4

(10-12)

\section{II.3. Descripción ética de la belleza}

Habría que hacer, pues, una segunda lectura de los ejemplos hasta ahora citados, partiendo de la afirmación de que el campo semántico

11 Para muestra sirvan: CP 26: 73, 19-20; 23: 66, 26-28; 102: 233; 103: 237.

CR 5v: 3, 61-65; 7r-7v: 4, 83-85; 25v: 9, 121; 60r: 25, 10-13/27-30; 107v: 83, 1-3; 108r-109r: $85 ; 110 \mathrm{v}: 90,9-12 ; 120 \mathrm{v}: 108,1-4$.

CST: $205-206 ; 22-226$. 
al que aluden palabras como «belleza», «fermosura», es más amplio que el específicamente físico. De hecho, es frecuente que las alusiones a la belleza exterior sean manifestación de una belleza de carácter ético. Entre los muchos textos se pueden recordar algunos que implican tal perspectiva:

Que nunca puede ser junto

en vn cuerpo perfeçión

saluo toda corrupçión,

pues en sy es tan corruto

(Vn frayle, CB 117v: 330, 5-8).

O casos como éste, en el que el Mariscal Iñigo niega que la amiga de Ferrand Péres sea «señora de sus señoras» (CB 191r: 573, 27), aduciendo que:

Non es costumbre nin vso

loar con tanta affeçión

la que en su disposiçión

Dios vna virtud non puso

(CB 192r: 576, 36-39).

Y otros que lo ejemplifican de una manera tan clara y rotunda como la «Copla esparça» de Santa Ffé:

\footnotetext{
Por capitán la cabeça puramente inclinada, muy devota humiliada, gran reverencia endreça. Los oios muy omildosos, non movidos mas suaves, quedos, honestos e graves, cobardes y pavorosos; alli do van deseando como bencidos e presos, piadosos et represos andan merçé demandando. Los orexas perçebidas, prontas, firmes, asaz quedas, sin rebato atendidas cada qual a su senyora a hoyr tanto se inclina que mostrando se indina con humil gesto adora. La lengua muy pavorosa se halla de razón folla, e la más ardit tremola, e la bien subtil non osa pensando en su Aymía, el fablar por maravilla
} 


\begin{abstract}
ella callando se humilla conosciendo senyoría.

Las manos asaz pesadas, tollidas, contrictas, juntas, bibas en son de defuntas, de bigor desnaturadas, comediendo en la celençia donde llegar se desean ni s'en mueve nin s'enplean en virtut de obediençia. (CP 132v: 278, 1-35).
\end{abstract}

Leyendo esta canción, transcrita casi en su totalidad, difícilmente podríamos hecernos la idea de la belleza física de la amada de Santa Ffe, pues ésta consiste más en la disposición, el carácter y el gesto de ella que en los rasgos corporales, y lo importante es que los rasgos físicos citados se convierten en correlato de humildad, honestidad, comedimiento, resumibles en el verso final: «en virtut de obediençia», virtud que, en todo caso, debería asignársele al amante, al poeta, al cortesano, al servidor y no a la amada, pues ésta es considerada por él como señora.

Ejemplos de este talante abundan en los cancioneros, por ello sólo entresacaré algunos: «prietos los oxos, mansos e suaues» (CP 155: 324, 22), donde tras un epíteto que apunta hacia una descripción física («prietos») encontramos otros dos adjetivos que hacen hincapié en la condición ético-moral que se les supone («mansos e suaves»). Referidos a tales circunstancias abundan otros como «dueña loçana, onesta e garrida» (CB 77v: 239, 2); «lindo rrostro, claro, onesto» (CB 13r: 24, 23); «graçioso e onesto rysso» (CB 75r: 231, 13); «oios ayuso» (CB 129r: $349,25)$.

Esta necesidad de purificar y ocultar el cuerpo que nunca, en el caso de las nobles amadas, aparece al desnudo, se suele resaltar frecuentemente con la descripción de la vestimenta, y con ello la descripción de la categoría social y las cualidades que se le suponen propias:

\footnotetext{
Vystiya una saya de pura cordura,

la su corta pisa era lealtad,

el su chapyrete era fermosura,

el su noble manto muy grant onestad;

estrado muy rryco con toda vondat,

los sus paramentos eran buen asseo,

e su gentyl cama, segund asy creo,

es que la cobría toda castidad.
}

(Pero Veles, CB 111v: 319, 25-32). 


\section{Magnificencia \& virtud, gracia, beldat, y nobleza, perla de la iuventud, seso de la senectud, caudillo de la destreza; reyna de la castidat, princesa de la corteledad, duquesa de honestidat, marquesa de la verdat: condesa de Castañeda.}

(Fernando de la Torre, CR 98v: 75, 1-10).

También es la castidad la primera calidad que se cita cuando Villasandino, a través de las letras del nombre de su amada - Catalina-, nos describe sus femeninas condiciones (CB 47v: 149).

En efecto, dos son las características principales a las que hacen referencia todas las alabanzas que tratan de diferenciar a la amada del resto de las mujeres: la castidad y la humildad. Encontramos fácilmente ejemplos de ambas junto a otros que se deducen de las anteriores, como comedimiento, bondad... He aquí algunos ejemplos:

Con lus son yguales en grand fermosura,

de todas las otras han grand mejoría

en pres e valor, beldat, cortesya

donayre acabado e mucha mesura

(Gómes Peres, CB 131r: 335, 8-11).

Graçiossa, muy fermosa

de muy linda fermosura,

amorosa e donosa

de angélica fygura,

muy pura criatura,

deleytosa

muy pollida e conplida

de bondades ssyn mansilla.

(Fray Diego, CB 164r: 504, 1-6; 9-10).

Grant sonsiego e mansedumbre,

fermosura e dulçe ayre,

onestad e syn constunbre

de apostura e mal vejayre.

(CB 78r: 240, 1-4).

Su fablar graçioso e onesto.

(A. A. Villasandino, CB 5v: 5, 33).

Vuestra lindesa e beldat, fermosura e onestat.

(CB 8r: 7bis, 9-10).

Seu falar e noble rrysso, 
lindo rrostro, claro, onesto,

ayre, lus de parayso.

(A. A. Villasandino, CB 13r: 24, 22-24).

Que ela ten tantas bondades,

alto brío e fermosura,

que por su noble mesura

non seredes oluidado.

(A. A. Villasandino, CB 13r: 25, 17-20).

Es fermossa con lyndez, traye muyta loçanía, de bondat e cortesya todos tienpos se guarnesçe.

(A. A. Villasandino, CB 19v: 46, 21-24).

Linda dueña enobleçida, noble de muy lynpia vyda.

(A. A. Villasandino, CB 54v: 176, 2-3).

Ya con tanta fermosura matades a quien vos mira, la virtud que'n vos espira engendra mucha locura.

(Diego Furtado de Mendoça, CP 3: 6, 1-4).

E después a onestat, iuro vos que le non yerra, que sus oxos en verdat nunca se quitan de tierra.

(García de Pedraza, CP 15v: 40, 21-24).

A la qual senyora mía las virtudes cardinales son siruientes especiales et le fazen conpanía, la moral filosofía iamás no se parte della con otra gentil doncella que se llama fidalguía.

(Enyego López de Mendoça, CP 40: 94, 89-96).

Servir en quien sienpre mora mexoría de bondades ffermosura con verdades

(Un hermano de micer el Tannedor, CP 82v: 172, 17-19).

Non te desplega saber que honestad te fase palaçio ser de castidat.

(Lope de Stúñiga, CST 4: 1, 81-84).

Non porque vuestra figura con muchas virtudes dos la cordura con mensura nin la vuestra fermosura 
eran nascidas, ni vos.

(Lope de Stúñiga, CST 6: 2, 20-24).

Dama de tales faciones,

Virtudes et condiciones

Que iamás fuessen sin par.

(Bachiller de la Torre, CST 25: 5, 83-85).

Tenes syn un sy muy grand fermosura, con habitud de clara bondad, gesto, donayre, gracia et mesura, con perfectión de vera honestad; modestia, temperança sin reguridad, qual se requiere a vuestra noblesa, por uso común con grand gentilesa regís vuestras fablas con moralidat.

(Iohan de Andújar, CST 193: 49, 25-32).

Como se puede observar en el elenco citado de ejemplos, pocos son los determinantes físicos que aparecen en torno a términos como fermosura o belleza ${ }^{12}$. Generalmente encontramos que las afirmaciones de belleza que van seguidas de algún elemento específicamente físico son utilizadas como trasunto de una descripción más ético-moral que físi$\mathrm{ca}$, y que incluso entre éstas nos encontramos muy a menudo con referencias al quehacer especial de Dios, que sería, en última instancia, quien justificaría con su trabajo no común que a la mujer se le pueda rendir vasallaje, como se hace con reyes y señores.

Mas no nos equivoquemos; lo específico del trabajo divino no consiste en que la mujer sea hombre perfecto, en que como el varón pueda tomar la iniciativa, pueda reír y hablar sin sonrojarse ni bajar los ojos, y menos que sea superior. No, la especifidad de esta obra divina consiste precisamente en subrayar aquellas cualidades que secularmente manifiestan su supeditación al hombre, tal como se interpreta a partir de la exégesis bíblica de la creación, incluyendo a San Pablo. En esta interpretación la mujer, por haber sido creada para la ayuda del hombre,

12 Podría continuarse este acopio de datos importantes para no errar e inducir a una lectura descontextualizada de los cuadros. Cito dónde pueden encontrare otros: $\mathrm{CB}$ 8v: 9, 39-45; 10v: 16, 5-8; 52v: 166, 9-10; 54r: 174, 28-32; 54v: 176, 11-12; 78r: 241, $5-8$; $105 \mathrm{r}: 301,9-16 ; 131 \mathrm{v}: 355,22-25$.

CR 4v: 3, 20-24; 14v: 6, 104-105; 22r: 11, 65-72; 60r: 25, 10-13; 83r: 52, 6-9; 91r: 64, 1-8; 95v: 74, 25-32;107r: 82, 11-17; 115v-116r: 96, 13-28; 120v: 109, 7-8;

CST 192: 49, 6-8;

CP 46v: 104, 3-5; 52v: 113, 44; 71: 148, 9-12; 85: 183, 9-11; 105v: 248, 9-16; 138-138v: 291, 9-17; 150r: 313, 29-32. 
debía mostrársele siempre humilde, obediente, sumisa, silenciosa, complaciente y fundamentalmente casta. En perfecta sincronización con esta ideología, alaban los poetas del cancionero a la dama porque entre sus cualidades se hallan la humildad, la castidad, la obediencia, la sumisión, el silencio, los gestos recatados. Sólo cuando se dan estas virtudes femeninas es digna de ser servida. El poeta se mofa cuando las mujeres saltan, cuando ríen estridentemente... No parece, pues, que de todo esto se pueda deducir que el amante se le someta, por mucho que la palabra servicio aparezca en los textos, puesto que aquellas cualidades que se le suponen al señor al que el vasallo rinde homenaje son contrarias a las que se exigen de la amada.

Por el contrario, la mujer adquiere connotaciones más de enemigo a quien hay que vencer que las de señor a quien hay que rendir homenaje:

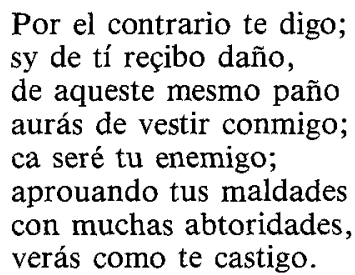

(Ferrant Sánches Talauera, CB 181r: 534, 65-72).

Y en ningún caso se le da la posibilidad de ser vencedora, puesto que el hombre desde el momento en que se presenta como amante se autodefine voluntariamente vencido:

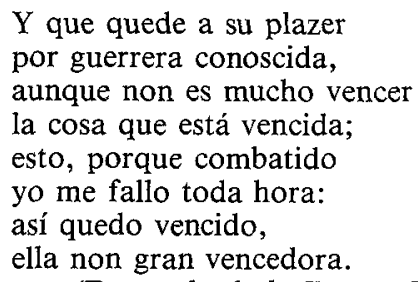

(Fernando de la Torre, CR 103r: 75, 2.24-231).

Si me sso a vos rendido non pienso que es error; siempre quedo vençedor ser de tal lugar vençido.

(Santa Ffe, CP 119v: 257, 1-4). 


\section{Conclusiones}

Es evidente que realmente no nos encontramos ante un acercamiento positivo a la mujer, tal y como durante mucho tiempo se ha dicho al hablar de la poesía cancioneril. Si observamos la distinción estamental entre villana/noble, por un lado, se puede ver indudablemente que las mujeres que podrían ser amadas eran minoría, y por otro lado observamos que los matices peyorativos no se reducen a las mujeres villanas, sino a las mujeres en general, de las que sólo se salvan aquella que los poetas singularizan, porque, como la Virgen $u$ otros personajes mitológicas, han merecido la fama por su castidad y otras virtudes asignadas históricamente como necesarias a la mujer.

Tampoco es cierto que la hermosura sea la causa principal del enamoramiento, aunque es evidente que a una mujer fea no se la tenía en cuenta. De todos modos, la hermosura es uno de los rasgos a los que más se alude -y también de manera más genérica - al hablar de las mujeres, las cuales, además de poseer belleza física, deben ser de una belleza espiritual que no contradiga la concepción vigente en todas las instancias sociales, incluyendo la Iglesia.

La divinización de la dama y el papel que en ello juega la voluntad de Dios o la Naturaleza no la dignifican como persona, según ha sugerido la crítica, puesto que se basan en la sublimación de las características de humildad y castidad que la dama debía poseer, y que son precisamente el índice de su inferioridad respecto al hombre.

Por tanto, Torrellas no está tan alejado de los que dicen hablar en defensa de las mujeres. Lo que le caracteriza es que las contradicciones implícitas en los demás las manifiesta en un solo poema «las calidades de las donas», con lo que resaltan de manera inequívoca y contundente.

Así, mientras para él las mujeres en general son inferiores, la dama a la que ofrece su poema debe ser excepcional. Esto se ve claramente comparando los versos siguientes y los que cierran las coplas:

Son todas naturalmente malignas \& sospechosas, non secretas \& mintrosas, $\&$ movibles ciertamente Mujer es un animal que se dize hombre inperfecto, procreado en el defecto 
del buen calor natural.

(CR 131v-133: 125, 55-58, 91-94).

Entre las otras soys vos

dama de aquesta mi vida, del traste común salida,

una en el mundo, de dos;

vos soys la que desfazéys

lo que contienen mis versos.

(109-114). 